\title{
Apparatus for grinding otoliths of larval and juvenile fish for microstructure analysis
}

\author{
Maria Karakiri, Hein von Westernhagen
}

Biologische Anstalt Helgoland, Notkestr. 31, D-2000 Hamburg 52, Federal Republic of Germany

\begin{abstract}
Recently the analysis of daily growth increments in fish otoliths has received great attention. Several preparation techniques have been developed for analysing otolith microstructure with light or scanning electron microscope. Most techniques refer to the preparation of larger atoliths $(>3$ $\mathrm{mm}$ ) and do not fulfil requirements for the analysis of otolith microstructure in juvenile fish. A simple and inexpensive apparatus for the grinding of small-size otoliths in larval and juvenile fish is herein described. It is basically a converted record-player allowing quick and precise plane grinding of small as well as larger otoliths, employing different grinding media.
\end{abstract}

Daily growth increments in otoliths have been reported for many freshwater and marine fish species in the laboratory as well as in the field (Pannella 1971, Radtke \& Dean 1982, Victor 1982, Eckmann \& Rey 1987). Readings of daily otolith increments made the ageing of tropical fish species possible (Ralston 1976, Schmidt 1980). Apart from information on the individual's age, otolith microstructure contains information on important events in the early life history of a fish and on the role of various environmental factors affecting growth (Campana \& Neilson 1982, Neilson \& Geen 1982).

As already pointed out in reviews (Campana \& Neilson 1985, Jones 1986, Brothers 1987), preparation techniques and methods of examination are of primary importance in otolith microstructure analysis and interpretation. Light or scanning electron microscopy (SEM), singly or in combination, may be employed for otolith examination. For fine structure analysis SEM provides more reliable results due to high resolution and lack of light artifacts. The examination of otoliths with the scanning electron microscope (SEM) requires particularly refined and gentle preparation techniques. The main steps in otolith preparation for examination under SEM are: (1) extraction of the otoliths from the auditory capsules, (2) cleaning from adherent tissues,
(3) mounting on SEM stubs in a mounting medium (e. g. Schellack), (4) grinding up to the midplane, (5) polishing the ground surface, (6) etching and (7) coating with an appropriate metal. Steps (4), (5) and (6) are of particular interest in order to obtain preparations that allow adequate and exact reading and interpretation of microstructures.

Grinding is the most important step of the preparation procedure. For accurate microstructure analysis, otoliths have to be ground on a single plane and exactly up to the midplane so that a clear continuous image of the incremental area from the nucleus to the outer edge is obtained. Grinding by hand, as frequently carried out (Wild \& Foreman 1980, Wilson \& Larkin 1980, Campana \& Neilson 1982), should be avoided in order to prevent edge overgrinding effects caused by forces exerted in a direction other than parallel to the grinding plane. For plane grinding, the use of an apparatus that assures a stable movement is necessary. An apparatus consisting of a transformed metallurgical jig has been described (Neilson \& Geen 1981) for otolith preparation, especially for the preparation of larger specimens.

The apparatus described here is much simpler in use, grants more precise grinding, allows easy control of the grinding process and may be employed for small, as well as larger, otoliths. It consists in principle of any commercially available record-player with a few technical alterations to enable it to serve as a rotary grinder. In place of a record, a glass disc is used for grinding, thus producing planar ground surfaces. The head of the record-player is replaced by a plexiglass fitting on to which the SEM stub with the mounted otolith can be attached (Fig. 1a, b). Different plexiglass fittings can be used for varius types of SEM stubs or even for glassslides with mounted otoliths.

Otoliths are ground against the rotating glass disc. 


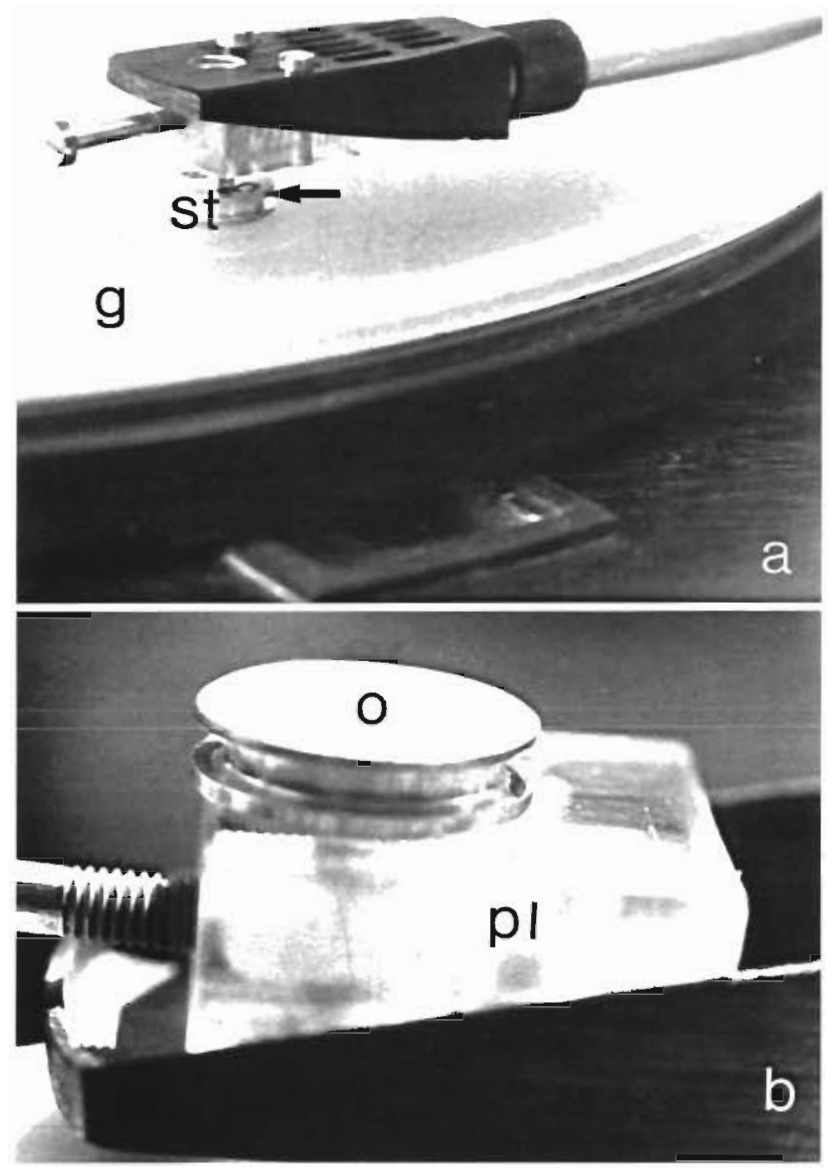

Fig. 1. (a) Converted head of record-player touching the glassdisc with an SEM stub (arrow); st: SEM stub with a mounted otolith, g: glass-disc. (b) The converted head upside down in detail; pl: plexiglass fitting, o: mounted otolith

The grinding medium (e. g. silicium carbide water mixture, grain size 2 to $6 \mu \mathrm{m}$ ) is applied on the glass disc. To retain water and grinding medium on the glass, the edge of the disc is provided with a silicon rubber wall $5 \mathrm{~mm}$ high. A plexiglass disc is used when polishing the ground surface of the otolith with diamond paste (1 $\mu \mathrm{m}$ ). The weight of the arm can be adjusted according to otolith size from 3 to $70 \mathrm{~g}$. Rotation speed can vary from 30 to $50 \mathrm{rpm}$. This allows the preparation of a sufficiently large size range of otoliths. Beginning with larval otoliths, up to 2 -yr-old fish otoliths, in the case of flatfish, may be ground.

The grinding process must be carefully checked until the midplane of the otolith has been reached. For this purpose the SEM stub with the attached otolith has to be examined as often as possible unter a binocular stereomicroscope. The midplane is reached when the nuclear area and the outer edge of the otolith can be recognized on the ground surface. The nuclear area is characterized by an optically higher density (in the case of flatfish) when viewed under a stereomicroscope. The recognition of the exact midplane level is a matter of experience with each fish species.

Otoliths of various fish species (flatfishes, blennies, coregonids, salmonids, tilapias) have been prepared with the described apparatus. Clear planar images of daily increments were obtained after grinding and viewing under an SEM (Fig. $2 a, b, c)$. The same apparatus can be used for grinding otoliths on one or on both sides for the preparation of thin specimens for light microscopical observation (Fig. 3a, b).

The advantages of this grinding apparatus are: (1) it is inexpensive, easy to construct and simple in use, (2) it provides accurate planar surfaces or thin preparates in a short time, (3) it can be used for small as well as for larger otoliths up to $6 \mathrm{~mm}$, (4) during the grinding process, specimens may easily be removed for monitoring and if necessary remounted in a fixed position for further grinding.

Acknowledgements. This study is part of a Ph. D. thesis by $\mathrm{M}$. Karakiri at the Faculty of Biology, University of Hamburg, supported by a scholarship of the German Academic Exchange Service (DAAD).

\section{LITERATURE CITED}

Brothers, E. B. (1987). Methodological approaches to the examination of otoliths in ageing studies. In: Summerfelt, R. C., Hall, G. E. (eds.) The age and growth of fish. Iowa University Press, Ames, Iowa, p. 319-330

Campana, S. E., Neilson, J. D. (1982). Daily growth increments in otoliths of starry flounder (Platichthys stellatus) and the influence of some environmental variables in their production. Can. J. Fish. Aquat. Sci. 39: 937-942

Campana, S. E., Neilson, J. D. (1985). Microstructure of fish otoliths. Can. J. Fish. Aquat. Sci. 42: 1014-1032

Eckmann, R., Rey, P. (1987). Daily increments on the otoliths of larval and juvenile Coregonus spp. and their modification by environmental factors. Hydrobiologia 148: 137-143

Jones, C. (1986). Determining age of larval fish with the otolith increment technique. Fish. Bull. U. S. 84: 91-103

Neilson, J. D., Geen, G. H. (1981). Method for preparing otoliths for microstructure examination. Prog. Fish Cult. 43: 90-91

Neilson, J. D., Geen, G. H. (1982). Otoliths of chinook salmon (Oncorhynchus tschawytscha): daily growth increments and factors influencing their production. Can. J. Fish. Aquat. Sc1. 39: 1340-1347

Pannella, G. (1971). Fish otoliths: daily growth layers and periodical patterns. Science 173: 1124-1127

Radtke, R. L., Dean, J. M. (1982). Increment formation in the otoliths of embryos, larvae and juveniles of the mummichog, Fundulus heteroclitus Fish. Bull. U. S. 80: 201-215

Ralston, S. (1976). Age determination of tropical reef butterfly fish utilizing daily growth rings of otoliths. Fish. Bull. U. S. 74: 990-994

Schmidt, R. E. (1980). Daily growth rings on otoliths for ageing young-of-the-year largemouth bass from a wild population. Progve Fish Cult. 12: 78-80 

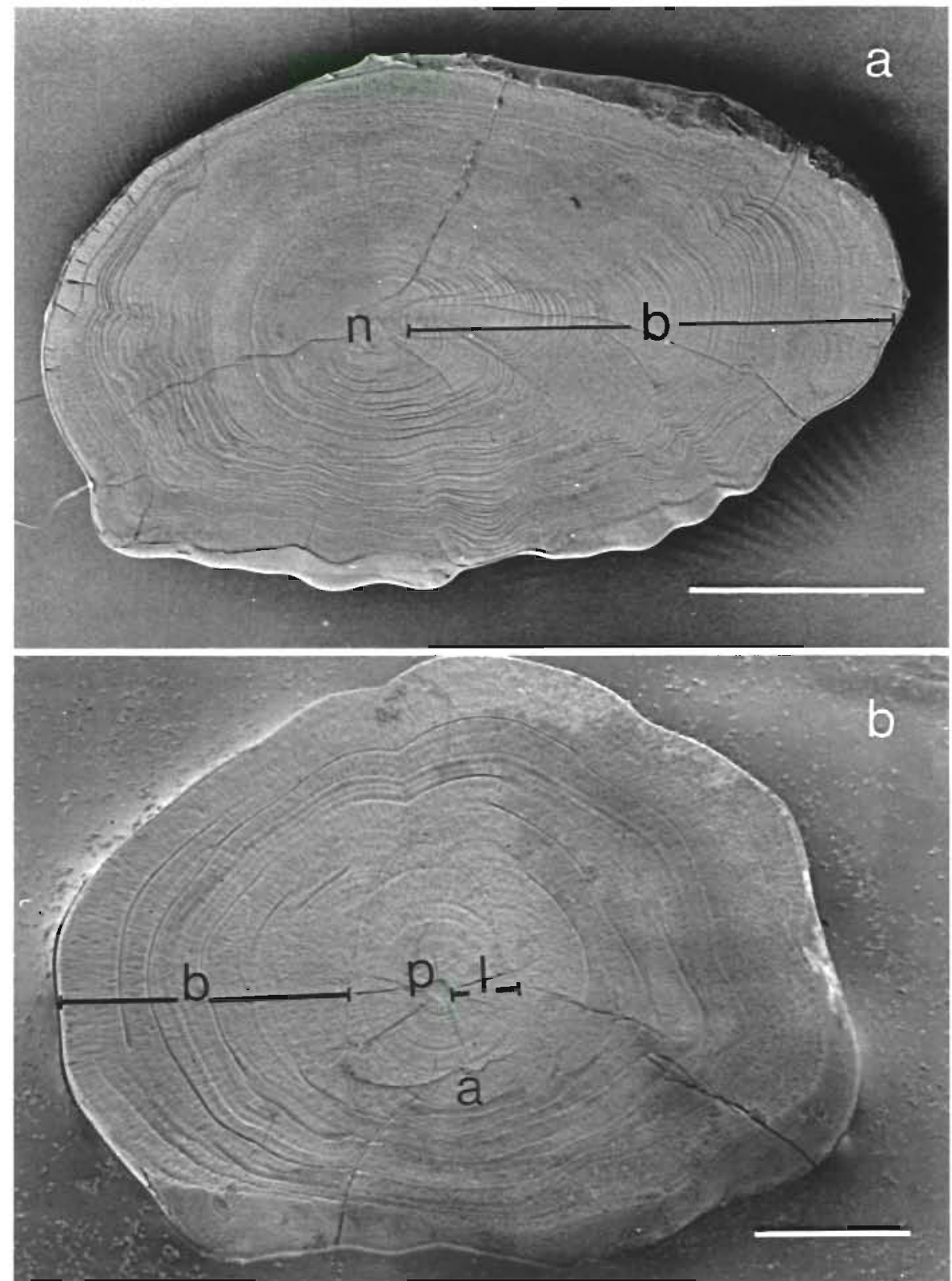

Fig. 2. (a) Limanda limanda L. Sagitta of a 3-yr-old dab from the Kiel Bight viewed in the scanning electron microscope (SEM). n: nucleus (primordium + larval phase), b: bottom-living stage. Bar $=1000 \mu \mathrm{m}$. (b) Pleuronectes platessa L. Sagitta of an 0-group plaice from the Wadden Sea viewed in SEM. p: primordium, l: larval phase, a: accessory primordium, b: bottomliving stage. $B a r=200 \mu \mathrm{m}$. (c) Outer edge of an 0-group plaice otolith as viewed in SEM. d: daily increment, s: subdaily increment. Bar $=100 \mu \mathrm{m}$

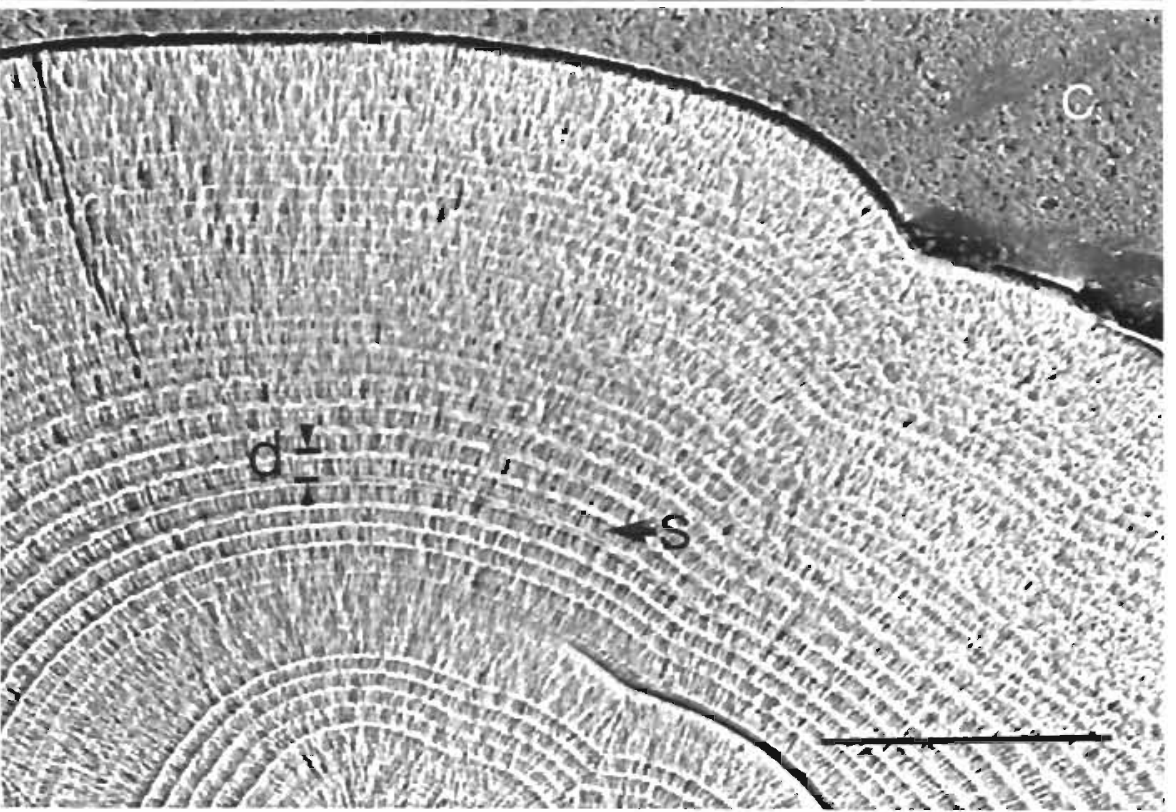



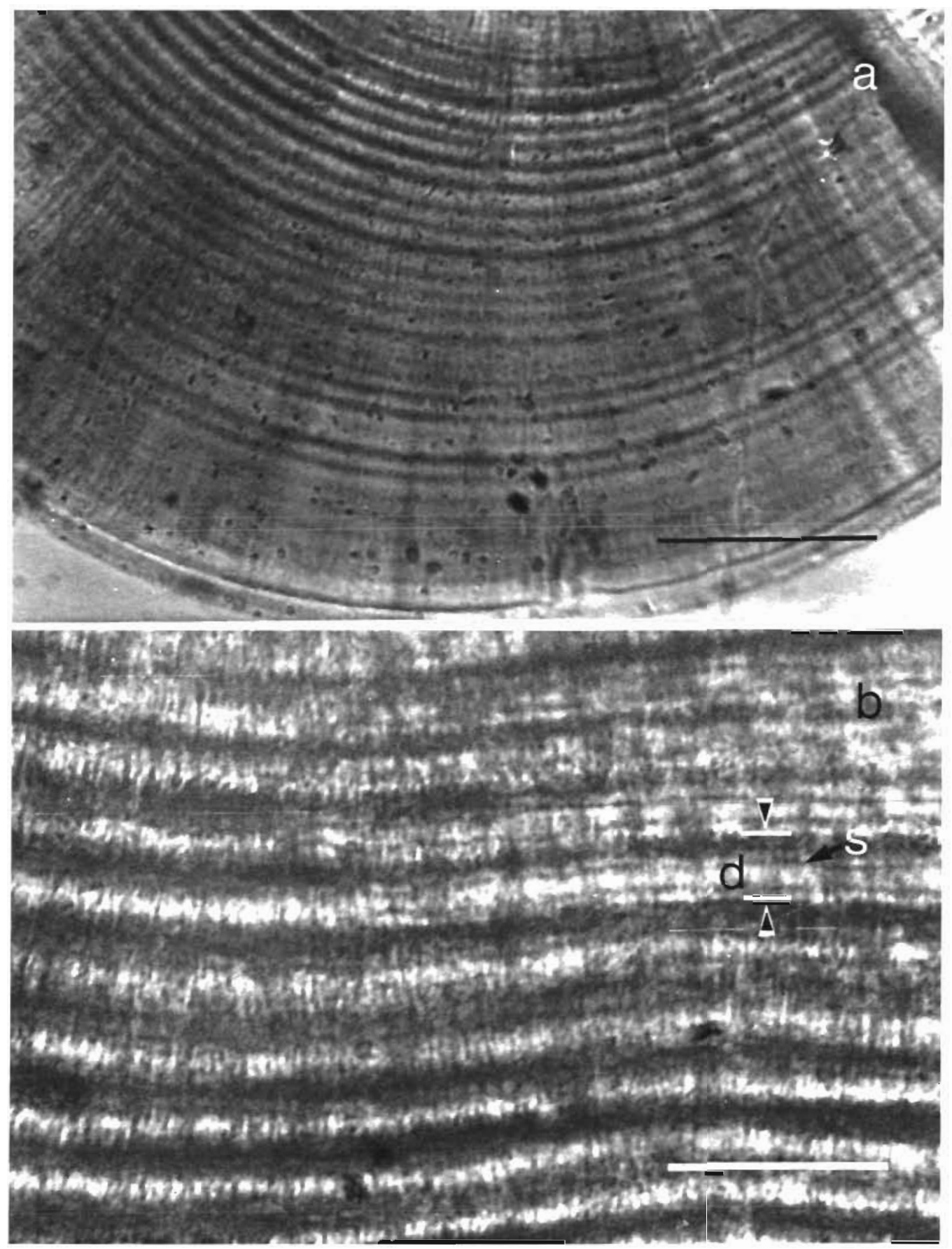

Fig. 3. Pleuronectes platessa. (a) Sagitta of a 50-d old, laboratory reared plaice larva photographed under light microscope (LM). The otolith has been ground on one side only. Bar = $12 \mu \mathrm{m}$. (b) Part of the sagitta of an 0-group plaire from the Wadden Sea, photographed under higher magnification under LM. The otolith has been ground on both sides. d: daily increment, s: subdaily increment. Bar $=20 \mu \mathrm{m}$

Victor, B. C. (1982). Daily otolith increments and recruitment in two coral-reef wrasses Thalassoma bifasciatum and Halichoeres bivittatus. Mar. Biol. 71 203-208

Wild, A., Foreman, T. J. (1980). The relationship between otolith uncrements and time for yellowfin and skipjack tuna marked with tetracycline. Inter-Am. Trop. Tuna Comm., Bull. 17: 509-541

Wilson, K. H. Larkin, P. A. (1980). Daily growth rings in the otoliths of juvenile sockeye salmon (Onchorhynchus nerka) Can. J. Fish. Aquat. Sci. 37. 1495-1498 